\title{
Creating Complexity in the Elementary Mathematics Classroom
}

\author{
Evan Throop Robinson \\ Correspondence: Evan Throop Robinson, Faculty of Education, St. Francis Xavier University, Antigonish, NS B2G \\ 2W5 Canada.
}

Received: January 11, 2021

doi:10.11114/jets.v9i3.5129

\author{
Accepted: February 18, $2021 \quad$ Online Published: February 20, 2021 \\ URL: https://doi.org/10.11114/jets.v9i3.5129
}

\begin{abstract}
Complexity thinking provides a unique perspective on classroom interactions, student engagement and classroom management as well as insight into innovative pedagogies for teachers in the elementary mathematics classroom. A novel meeting strategy for classroom organization offers teachers the opportunity to observe complexity in action and to promote student participation through mathematical conversations thereby building the learning community and fostering the discourse of mathematics. The intervention of mathematical conversations created conditions for complexity in an elementary classroom and provided qualitative data for analysis. Transcripts and classroom mapping showed increased student engagement with students afforded more freedom, mobility and choice to host or participate in small-group conversations. An analytic framework indicated three types of conversations emerging: sharing information, building knowledge and exploring possibilities as well as instances of blocking behavior. Findings suggest possibilities for building student capacity for conversation skills, disciplinary integration and differentiating learning significantly for students.
\end{abstract}

Keywords: elementary mathematics, complexity thinking, mathematical conversations, classroom discourse

\section{Introduction}

That chaos and complexity theories are being used to interpret classroom and the human dynamics of teaching and learning suggests fidelity of these theories for significantly changing the way we come to know and shape our world. (Fleener, 2009)

William Doll's book, A Post-modern perspective on curriculum (1993) challenged traditional approaches to curriculum development and classroom instruction and opened the door for educators to re-examine their practice in light of complexity (Davis, Smith \& Leflore, 2008; Davis \& Sumara, 2006; Doll, 2012; Fleener, 2002; Kieren, 2003). In what has become a classic of complexity thinking literature, Doll laid down a theoretical foundation for understanding the principles of chaos and complexity in teaching and learning. His earlier research study (1989) in a middle school mathematics classroom introduced complexity thinking to educators with a teacher's perspective on a complex system in action. The research allowed students flexibility in their intellectual and social organization to solve mathematical problems in their own way and in their own time. While randomness, unpredictability, and chaos were evident, Doll also noted a new type of order emerging, one he described as, "progressive, constructive, personal, and interactive" (p. 66). One critical finding in this classroom research showed that:

The entwining of chaos with order occurs universally and can be seen in all student learning. Self-organization is a feature of all nature, and certainly evident in students' developing their own creative powers. To see how complexity can emerge from simplicity requires only that we study and teach our subjects - at any level - with depth, not superficially (Doll, 1989, pp. 69-70).

This inspired me to pursue my own mathematics classroom research and to find simple methodologies that would promote interactivity, accountability and creativity among students, allowing complexity in the classroom to emerge.

Author and consultant, Harrison Owen (1997) provided me with an example of one such methodology, which he calls Open Space Technology (OST). OST, which I describe in full detail below, evolved as Owen introduced circle conversations to groups looking to self-organize pragmatically around common issues. He described OST, first, as a 
means of increasing meaningful communication and, second, as a way to build on existing networks within an organization. He also described OST as complexity thinking in action (2000). Bringing OST to the mathematics classroom was an opportunity to observe complexity in an educational context and, specifically, for students engaging in mathematics. My research asked: How might OST promote student participation to build learning communities that foster the discourse of mathematics?

As a former elementary teacher and now, as a researcher in mathematics education, I focus primarily on those instructional strategies that create vibrant learning opportunities for students and afford them significant opportunity to express their understanding in ways most meaningful for them. The circle conversation is one such methodology that supports students' communication of mathematical understanding, their participation in collaborative problem-solving and mathematical thinking. In this article, I first provide an overview of the theoretical perspective of complexity thinking in education through an imagined circle conversation among key thinkers in this field. I then introduce the OST methodology as an expression of complexity thinking in action, together with the tools and adaptations I devised to support implementation of OST in an elementary classroom. I conclude with a summary of findings and implications from the research study to make this methodology accessible to teachers and researchers who wish to join the conversation around complexity thinking in education.

\section{An overview of Complexity Thinking in Education}

The conversation that ensues is an imagined series of conversation circles of select key thinkers in complexity thinking. Among them are Steven Johnson, Scott Camazine, Warren Weaver, Margaret Wheatley, Albert-László Barabási, Melanie Mitchell, Fritjof Capra, and Stuart Kauffman. Johnson opens my imagined conversation with a brief summary of his findings regarding the phenomenon of complex adaptive systems as they exist in nature.

\subsection{First Circle Conversation in Complexity}

Steven Johnson: It's official! We have a best-selling book in complexity thinking and I can thank each of you for helping me pull it together. It's called, Emergence: The connected lives of ants, brains, cities, and software, (2001) and it offers my observations of natural systems. I described the complexity of the ant colony behaviorally as the, seemingly, chaotic exchanges and interactions between ants. The emergent colony is unachievable by any single ant acting alone, regardless of effort or skill. The collective, working 'chaotically' however, is capable of producing a complex system. I found close observation of ants, for example, to reveal individual ants adhering to simple rules of interaction with a small number of ants based on their acute sense of smell rather than their poor sense of vision.

Scott Camazine: I observed something similar in birds flocking (2003). Coordinated flocking appears to rely on three simple rules for maintaining separation, alignment, and cohesion among flock-mates: steer to avoid crowding or colliding with nearby birds; maintain the average heading of nearby birds; and move toward the average position of nearby birds. As I explained in my research, "Despite their simplicity and the local range of their immediate effects, the rules and their actions on the subunits give rise to the spontaneous emergence of pattern, order, and structure on a global, system-wide scale" (p. 36).

Johnson: I phrased it somewhat differently when I wrote about a colony created through "a system with multiple agents dynamically interacting in multiple ways, following local rules and oblivious to any higher-level instructions" (p. 19). Intriguingly, order emerges from apparent chaos and so one might well wonder: What drives ants to interact in this way? What are the local rules that each ant must adopt to create a colony? Or, how best to describe such natural phenomena?

Warren Weaver: Great questions! Let me see if I can give you some insight and clarify this phenomenon of emergence as you have observed it with ants and birds. I was thrilled to be one of the first researchers to describe complexity for the scientific community (1948) and articulated for many a hot debate running at the time. On the one hand, we have scientists taking the perspective that all things are reducible to their component parts for analysis and on the other, some researchers, particularly in the social sciences, holding that incremental changes in systems can lead to far-reaching, qualitative changes that are different from, and irreducible to, their parts (Stanley, 2009). We saw this as the New Science though many researchers studying complex systems in the natural sciences and social sciences bestowed different names on the subject, including Chaos Theory, Non-linear dynamics, The New Science, and Complexity Theory (Gleick, 1987; Prigogine \& Stengers, 1984; Waldrop, 1992).

Me: Aristotle's aphorism: the whole is greater than the sum of its parts, sums this up nicely.

Weaver: Yes! In Education, some researchers have adopted the term complexity thinking to describe this complex phenomenon and the possibility of collective wisdom (Surowiecki, 2004) from school systems to classroom settings and the individuals that gather there. 
Margaret Wheatley: We've been speaking of relationships among individuals of a complex system in our research (Wheatley \& Kellner-Rogers, 1999) to describe possibilities for organizations to restructure into more meaningful and productive entities. This could be termed emergence, though I described it as, "The surprising capacity we discover only when we join together" (p. 67). Here, let me draw you a quick diagram that Cross, Parker and Sasson used to illustrate what I mean. The diagrams below show, on the left, an organization chart which represents the organization's reporting structure. On the right is a map created to show how the information exchanges flow within the same organization.

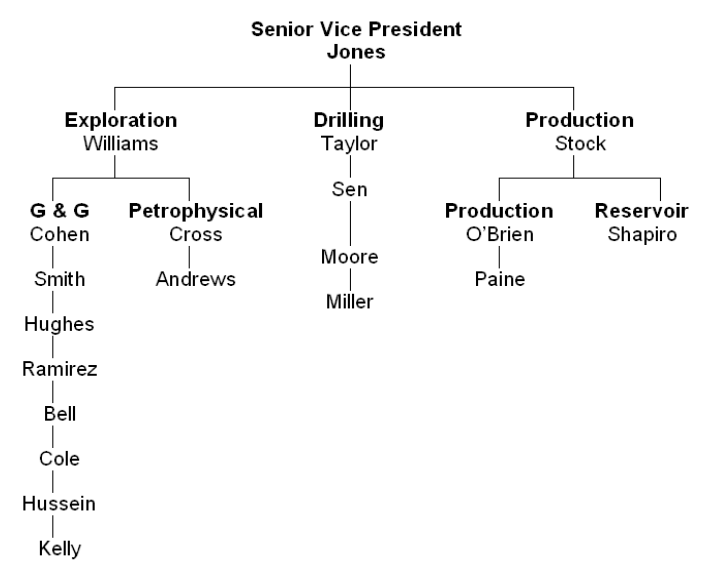

How Work is Organized

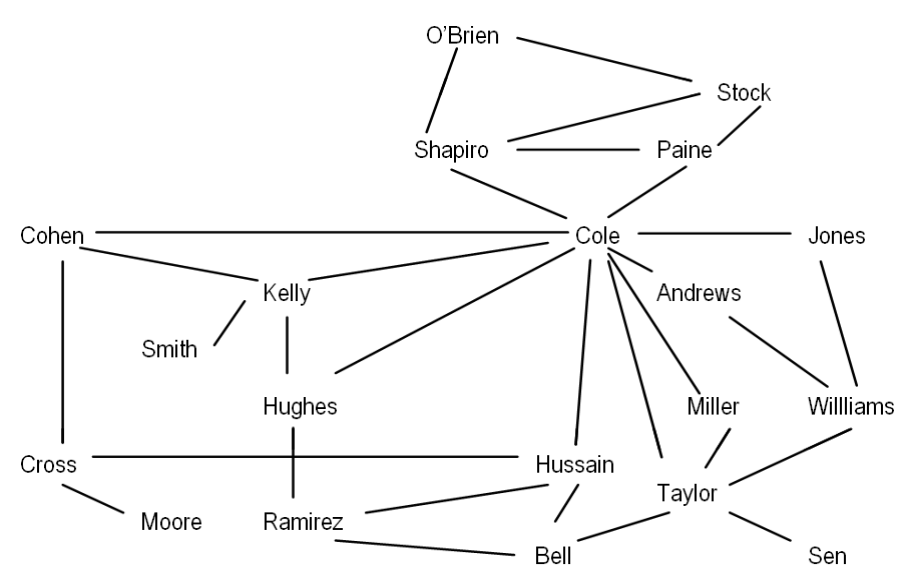

How Work Really Gets Done

Figure 1: How work is organized (source - Cross, Parker \& Sasson, 2003, p. 6)

Clearly, one employee, Cole, while close to the bottom of the hierarchy, attracts more energy in the network than others, including Jones. As Senior VP, Jones sits atop the chain of command though, in reality, only holds two meaningful connections, including one with the network's main attractor. It is his connection with Cole, not his position on the organizational chart, which links him to the network in a meaningful way. The network map illustrates how work really gets done in this system, in contrast to how reporting lines run.

Albert-László Barabási: I'm not surprised. This is consistent with our research into social networks and the interconnected nature of our human existence (2003). They even made a movie about our work! Remember Six degrees of separation? (Kidney \& Schepisi, 1993). Our work prompted people to talk about connections, relationships and how networks emerge, often from very simple rules of engagement. In studying the connectedness of the World Wide Web, for example, we used the term "scale-free network" (p. 70) to distinguish it from a more evenly distributed or random network. In the scale-free network, we observed nodes or hubs with significantly more connections than others, very similar to the diagram showing how work really gets done.

Melanie Mitchell: My research into networks (2009) built on this and looked at differently organized systems. First, the centralized network, like in the organizational chart example, demonstrates a highly efficient flow of information; yet, it is vulnerable to frequent breakdown given the 'one-way' links between nodes in the system. Second, we examined a modified system that distributes more links more evenly among its nodes in order to strengthen it, as some nodes could be removed without affecting the entire system. However, in this case, the distributed system was no longer efficient given the lengths that information needed to travel from node to node. Thirdly, we proposed a more efficient and sustainable network in a decentralized system whereby sufficient nodes remain well linked but not over-connected. This maintained the viability of the network even if some nodes were removed or functioned poorly (Baran, 1964; Davis \& Sumara, 2006). I think a diagram of each would clarify our research. 

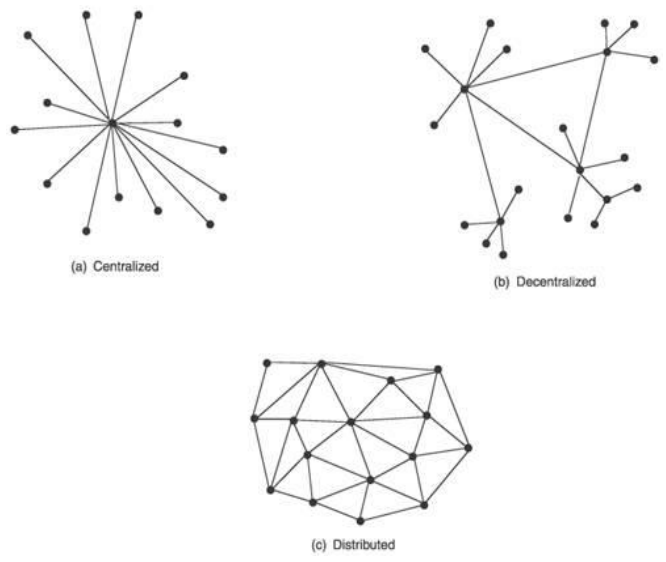

Figure 2. Centralized, decentralized and distributed networks (Baran, 1964; Davis \& Sumara, 2006)

Camazine: Imagine a world without supervisors, administrators, and managers, and many people would imagine sheer chaos!

Mitchell: Indeed. Nevertheless, without centralized control, self-organization in nature is efficient, economical, and ubiquitous. It is one of the least known, yet most powerful, devices for achieving pattern and order in the world.

Me: This is an important feature of complexity for educators to consider. How might teachers build on the concept of networks and viability of a system, without overly centralizing control or distributing to the point of too much inefficiency? The decentralized option allows for both autonomy and shared connections. Further exploration of these facets of complexity thinking in the classroom is needed, as many observations of the natural world or in business networks are specific to their environment and particular to their unique conditions. Research in the classroom with its multifaceted dimensions may encounter new or different possibilities from these studies.

Capra: Let's go back to the issue of self-organization for a minute as it may provide some insight into the dynamics of the classroom. For me, the ability of a system to self-organize rests on the nature of the relationships and interdependence of psychological, biological, physical, social, and cultural phenomena within that system. That's why I wrote my well-known book, The Web of life (1996), to explain these interrelationships and my systems view of life. I tried to bring together the work of many thinkers exploring living systems and asked them to shift their research focus from the objects they study to the relationships that develop among the objects. As I wrote, "In the systems view we realize that the objects themselves are networks of relationships, embedded in larger networks. For the system thinker the relationships are primary" (p. 37). Complexity thinkers must consider not only the objects within a system, but how they are connected within the system, how their interactions form networks, and, most broadly, how networks form relationships with other networks.

Me: Your perspective prompts me to consider a shift in the traditional research focus from the individual students and teacher in the classroom toward a more systemic view of the classroom as a network of student-student and student-teacher relationships (Bai \& Banack, 2006). In any classroom there are a variety of networks interacting with each other to create the entire learning system. This theoretical focus prompts teachers and researchers to pay close attention to such networks as they arise in classroom activity. It also raises important questions about these relationships: What networks, if any, will form in the classroom? How do student-student interactions and student-teacher interactions change over time? And, in what ways do various networks interact within the complex learning system of the classroom?

Capra: Yes. My observations of living systems suggest that there exists for all members of the system a mutual dependence or interdependence on the others in order to remain viable. Without interdependence the system would become unsustainable and die. We must consider carefully the interdependence of relationships in our efforts to understand the living system for, "A sustainable human community is aware of the multiple relationships among its members. Nourishing the community means nourishing those relationships" (p. 298).

$M e$ : Clarifying in what ways this nourishment manifests itself, if at all, in the classroom may provide insights for future research in education.

Stuart Kauffman: I'd like to jump in here too, if I may? Our research in complexity (1993) brings to light other key facets that need our attention if we are to understand more fully the sustainability and viability of a complex system; namely, adaptation and the edge of chaos. 
Capra: We've always talked about how nature seeks equilibrium to create order from chaos, haven't we?

Kauffman: Yes, and the edge of chaos became important to us as we began to consider in what ways a system might adapt to maintain viability during periods of order and chaos. A system demonstrating too much order does not hold enough variety or diversity to adapt and therefore sustain itself, while a system with too much disorder or chaos will quickly break down from too much 'noise' thus limiting opportunities for adaptation as well. What is required then for a sustainable system is just enough order and just enough chaos to promote viable adaptations that enable it to exist 'on the edge' between the two. Our scientists used the term edge of chaos $(1995$, p. 27) to describe water molecules in transition from a solid state, to a liquid and finally to a gas as temperature increases. The edge of chaos denotes the boundaries from one phase transition to another as molecules adapt to a new state. We have also observed adaptive behavior and phase transitions in living systems as they function between order and chaos, on the edge as it were, to maintain their evolutionary 'fit' for survival and viability in times of change.

Me: The edge of chaos metaphor is particularly apt, in an educational sense, for school systems like the classroom, and for epistemological perspectives concerning the general nature of knowing and learning. For the learner, edge of chaos denotes the boundary between previously held knowledge and belief constructed through experience, and what is yet unknown. Learning, through the lens of complexity thinking, denotes the transition between the two states as students adapt and change with new understandings. Too much order stifles the construction of new knowledge, since the system requires no adaptation to the unknown; just as too much chaos inhibits connectivity. Potentially, students learn during the transitions between order and chaos: they adapt prior knowledge to new experiences mediated by peer interaction.

Kauffman: The relationships and interactions among individuals within a complex system are not rigidly set in place but rather change and are modified as needs arise. To function otherwise would result in strict and inflexible bonds, incapable of modification, and likely resulting in complete collapse of the system.

Me: So, opportunities for adaptation become a complex system's fundamental strategy for survival as changes within the system create transformative possibilities for emergence. In the classroom, emergence denotes a shift in previously accepted ways of knowing and being. I'd like to invite a number of scholars who are also undertaking research in education to join our circle and continue the conversation with their insights into the educational possibilities of complexity.

\subsection{Second circle conversation in complexity and education}

We are joined by a group of educators, Brent Davis, Dennis Sumara, Sarah Smitherman-Pratt, Harrison Owen and Chris Corrigan, that seek ways to facilitate emergence and promote complexity thinking in schools. Capra interjects abruptly.

Capra: Wait a minute. We found that applications of complexity thinking first arose in business and related professional studies on organizational development, leadership, and change management. Consider Baskin, (2005), Olson \& Eoyang, (2001), and Senge et al., (2000) just to name a few. Now you're telling me the teachers are into this?

Brent Davis: Absolutely. Educators are excited about the possibilities of understanding their work in complexity thinking terms. Many teachers seek integrated, cross-curricular innovations for teaching so why not embrace the same philosophy in our research into educational phenomena?

Capra: Yes, but wasn't it Yorks \& Nicolaides who said, "Complex systems are characteristically dynamic and usually annoyingly unpredictable, anathema to outcome addicted organizational mind-sets and practices?" (2006, p. 145). Certainly school systems would fall into this latter category, would they not?

Davis: Consider the current focus in education on linear-based curriculum outcomes and models of standardized testing, which confirm or negate students' achievement and learning in various disconnected disciplines. Complexity thinking provides an entirely different way of observing complex phenomena like education and learning (Davis \& Sumara, 2005). In complexity thinking terms, the dynamic nature of the classroom, to paraphrase Radford (2006), describes an interconnected, complex system of changing and adapting relationships that seeks viability through self-organization. We are a long way from a static, linear view of the classroom where organizational structures (i.e., hierarchical structures, scheduling demands, isolated curricula, etc.) maintain centralized control over others and inhibit collective, creative possibilities.

Dennis Sumara: Maturana \& Varela talked about knowledge in complexity thinking terms as well. They highlighted action or, more specifically, interaction in the generation of emergent knowledge when they said, "All doing is knowing and all knowing is doing" (1987, p. 26). Their term, enaction, recalls the necessary action involved in shaping our experiences and knowledge.

Me: So it is through student-student interaction that collective knowledge emerges? 
Davis: Exactly. Well, at least that's what our data shows may be happening. We coined a new term for our research, knowledge-as-(inter)-action (Davis \& Sumara, 1997, p. 110) to focus attention on the collective and their efforts to nurture emerging understandings through conversation and shared action. Subsequent research suggested that making ineffective distinctions between learner-centered and teacher-centered teaching approaches might hamper development of a more knowledge-centered pedagogy that views the learner in the collective and mathematical knowledge arising in interaction (Davis \& Simmt, 2003).

Me: Knowledge-as-(inter)-action recalls the exchange of ideas, questions and resources that occurs through OST too.

Davis: Complexity thinking asks educators to avoid notions of causality and effect in their teaching, which presumes one might be able to cause emergence in the classroom. Rather, complexivists tend to think in terms of occasioning emergence; that is, providing the conditions necessary to sustain the complex system. Complexity thinking, then, asks teachers to avoid planning what will happen in their classroom and occasion what might happen if the appropriate conditions were available.

Me: The intent of OST is to create those minimum conditions for complex activity to arise and so, potentially, occasion emergence, notwithstanding the complicity of the researcher (Kincheloe \& Berry, 2004) who has introduced this methodology in the classroom.

Davis: We have found complexity's minimum conditions critical as well. Let me describe briefly the five conditions our research has shown may increase the probability of emergence for students:

1. Internal diversity - each member brings unique perspective and concerns to the collective as members contribute in diverse ways to the community;

2. Redundancy - sufficient commonalities of experience, background, etc. provide for a common sense of purpose for the community;

3. Decentralized control - no one in particular directs in the system, the collective emerges;

4. Organized randomness -minimum principles for group dynamics, also known as enabling or liberating constraints (Davis, Sumara \& Luce-Kapler, 2000), determine boundaries of activity without limiting possibilities; and,

5. Neighbor interactions - the ideas and words of students must mingle and mix through exchanges and conversation with each other (Davis \& Simmt, 2003).

Me: This is useful with respect to my OST intervention. Acknowledging the internal diversity and redundancy of the classroom is key to appreciating more fully the dynamics of the classroom. Notwithstanding the obvious importance of the teacher's role in the classroom (Herbel-Eisenmann \& Cirillo, 2009; Nathan \& Knuth, 2003; Pierson \& Whitacre 2010), decentralized control becomes an essential pedagogical shift in my research with the teacher and researcher present but neither leading. In OST, organized randomness takes the form of four principles and one Law of Mobility. These provide liberating constraints: enough structure to guide but enough freedom to create possibilities as students engage with their chosen topics. And, with this freedom to move about the space, opportunities for neighbor interactions arise as ideas come together in conversation.

Sarah Smitherman-Pratt: I, along with others (Dalke \& McCormack, 2013; Kiefer, 2006), also provide descriptions of the classroom in complexity terms. Specifically, I set out to understand more fully the complex conversations that I saw emerging in my methods courses (2006). By observing complex conversations, I hoped to show that the sharing of differences, multiple perspectives, and authentic questions give rise to new ways of knowing, "where ideas do not converge or diverge but co-emerge" (p. 167).

Me: I take this work into the elementary school to observe how OST might foster such complex conversations with children and interrupt previously held notions about the role of the teacher and of the students. Atkins (1997) adopted a non-traditional approach to mathematics instruction and problematized conversations in her classroom as proofs and refutations (Lakatos, 1976). Atkins' findings suggested that student conversation may contribute to the development of collective mathematical knowledge; although, even as her approach models many OST aspects, her analysis of the classroom event provided only a glimpse of the students' participation in the discourse of mathematics.

Harrison Owen: My work with organizations often showed that rigid, hierarchical structures stifled creativity and innovation. When people voluntarily come together, within an invitational space that forms around minimal conditions, meaningful exchanges occur in conversation, laying the foundation for creative possibilities.

Davis: Set in an educational context, this conversation, for me, is distinct from discussion. As I wrote:

Quite unlike the discussion, then, the conversation is fluid, meandering its way toward a 
destination that is not specific, but that will be commonly known. That the destination is unspecified and unanticipated is the strength of the conversation, for, by being unconcerned with reaching a particular point (i.e., relinquishing the modernist desire for control) - by allowing the path to be laid down in walking - the participants are able to listen to the particularities that shape that path. The goal of the participants in a discussion, much in contrast, is often to remain rigidly in place, to be unswayed (1996, pp. 27-28).

In this way, as Smitherman (2006) concurred, conversation implies a way of being with others who come together to listen, share and consider ideas.

Me: An OST approach in education could promote such a conversation. With practice in generating meaningful exchanges (Seedhouse, 2010), students may clarify or advance their conceptual understanding of mathematics.

Owen: The goal of OST is emergence leading to convergence. If emergence (i.e., new ways of thinking, or, in essence, learning) happens when people within the system experience meaningful exchanges or exchanges of value then this may become an effective approach in schools. If such emergence leads to convergence (i.e., changes to the system itself through adaptation and self-organization) then such transformational education and innovation could benefit all learners.

Me: This is the challenge for the elementary mathematics classroom teacher: to promote an environment that allows for meaningful exchanges that are sufficiently strong yet not so strong as to limit the opportunities for learning (Newell, 2008).

Corrigan: My facilitation of OST with adults led me to consider the applicability of using the methodology in children's education. At this point, I am only able to contribute to a theoretical discussion (2002) as I did not extend this to the practice level. However, I might offer insights into students' empowerment in holding the space for their own learning to allow creativity and freedom to emerge. As I said, "Power is not meted out like a ration, but rather is left for people to take as little or as much as they want.... This is true empowerment, because participants are invited to become empowered to the extent that they wish" (p. 2). I caution OST facilitators about freedom shock or the state of anxiety that comes from experiencing unprecedented amounts of freedom, choice, and responsibility in participants who may have never felt freedom in this way (p. 3).

Me: Thank you all for your contributions to this conversation. Your overview of complexity in education and in action through OST suggests a need for further inquiry and research. Sfard (2008) encouraged researchers to accept "a patchwork of metaphors rather than a unified, homogeneous theory of learning" (p. 12) in their work. Complexity thinking offers a compelling lens through which to view classroom research. I am not aware of previous research using OST in the classroom. OST may provide the methodology for this student interaction and for meaningful exchanges to arise.

\section{The OST Methodology as an Expression of Complexity Thinking in Action}

Research clearly asserts that conversations are critical to ensure students make sense of and clarify their understandings in mathematics (Smitherman-Pratt, 2009). Perhaps less clear for teachers is how best to promote mathematical discourse and facilitate students in mathematical thinking through peer-to-peer interaction and talk. While complexity thinking offers a unique perspective for educational researchers to view classrooms and schools, appropriate methods and tools are not yet universally developed, as Davis \& Sumara caution, "Complexity thinking explicates, (for example), the importance of neighbor interactions, but offers little generalizable advice on means to accomplish the meeting and blending of ideas" (2006, p. 143).

OST offers teachers a methodology that they can incorporate in their approach to mathematics education. It empowers students to become active participants in their own learning while the reduced role of authority, found traditionally in the teacher, becomes a shared responsibility among the students. OST places the onus on students to self-organize around topics they feel are important to discuss and so warrant fuller and prolonged engagement. OST also ensures that all students are given full choice over their actions and full accountability for their learning so the issue of compliance becomes irrelevant, as the system accommodates all degrees of participation. Therefore, there is no need to opt out or remove oneself entirely from the system.

\subsection{Setting Up OST in the Classroom}

The OST space contrasts significantly with what students view as the conventional look of the classroom. Classrooms need enough space for a circle of chairs (one for every participant). All other furniture is removed, if possible. Ideally, the classroom is large enough to create other smaller circles of chairs for breakout conversations (Figure 3). 


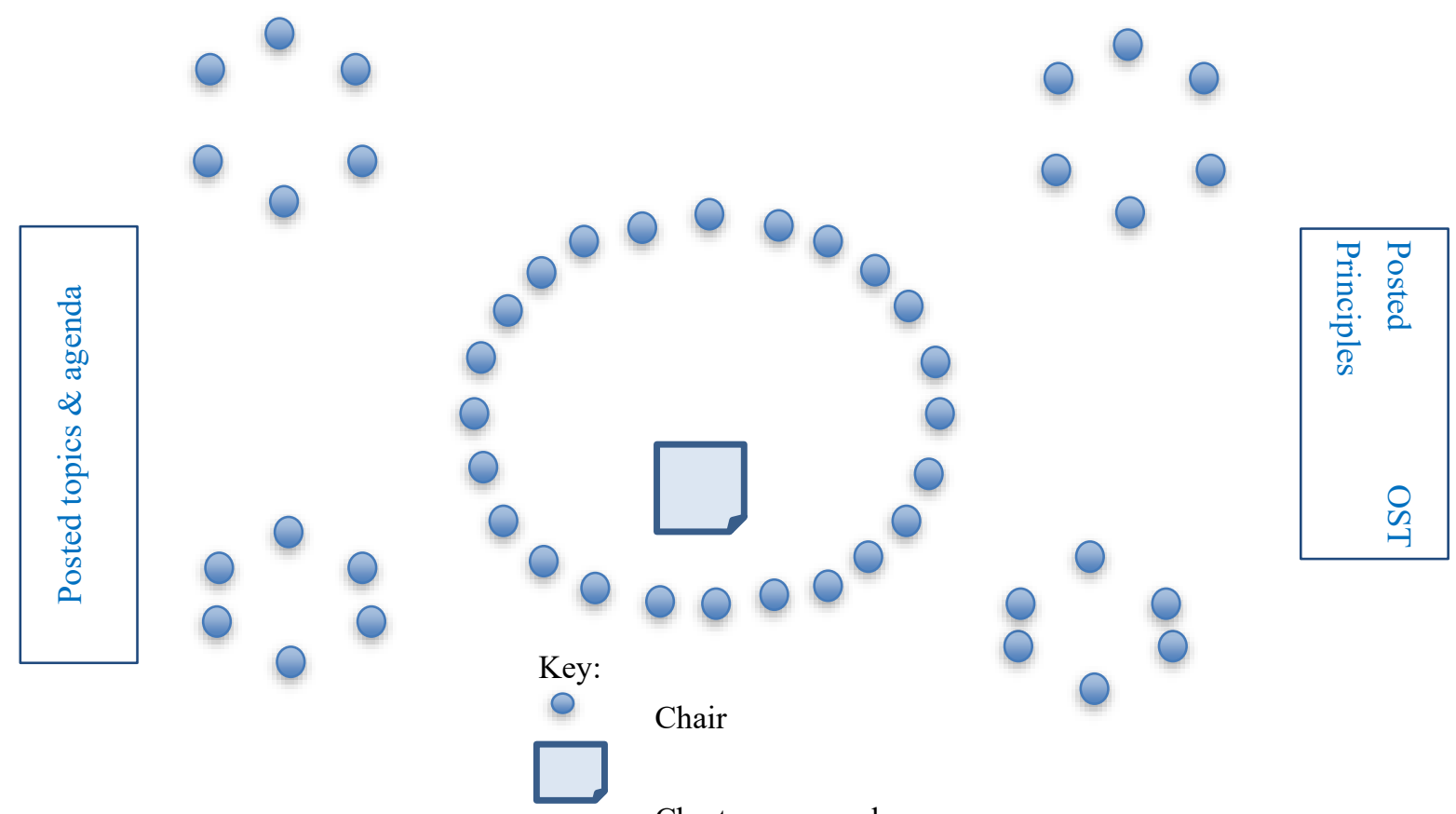

Chart paper, markers

Figure 3. Classroom set-up for OST

This is the physical open space that allows for student movement. The open space permits fluidity of thought as ideas literally bump into one other (Davis \& Sumara, 2006) as neighbor interactions increase. The phenomenon of self-organization emerges as students come together and share this common space of learning. The teacher, now facilitator, holds space for self-organization and does not direct or instruct those within it. To begin, all participants sit in the large circle, while the facilitator welcomes everyone and highlights the key theme for the session. Owen describes the circle as "the fundamental geometry of open human communication" (1997, p. 5). The circle removes the traditional focus of authority from the head of the room. Sitting in the circle on chairs without tables or desks allows people to see each other face-to-face, underscoring that everyone holds power around the circle and participation is open to all (Mirsky, 2014). As Owen states, "When everybody, no matter their rank or position, sits on the same level, eye-to-eye, with nothing in the way, an extraordinary powerful statement is made about equality of participation, and the conditions for a truly collaborative effort are created" (1997, p. 70).

\subsection{The Four Principles}

Owen suggests four principles descriptive of the way things work in open space. As Owen states they are important “...but never to be taken with total seriousness" $(1997$, p. 95). The first principle of OST is: Whoever comes is the right person. It is not necessary to have many people join a conversation, just those people who care the most about that particular topic. Even if only one person comes, it provides an opportunity for one person to focus their thinking and writing on the issue. The second principle of OST also underscores this self-organization: Whatever happens is the only thing that could have. Students let go of expectations and work with whatever unfolds in a space that is intentionally not teacher-directed; becoming, in complexity terms, a collective, knowledge-centered system of learners. The freedom encouraged within the OST space energizes students, creating the conditions for engagement (and fun) with the topic at hand, rather than disengaging or becoming unfocused.

Two other OST principles complete the simple rules of engagement to provide an orientation conducive to exploration, often leading to unexpected results, or a deep simplicity (Everett, 2011) of understanding. These are: Whenever it starts is the right time and When it's over, it's over. These serve as reminders that creativity does not happen on a schedule and allows everyone to enjoy the flexibility of relaxed time constraints. Moreover, if a group finds a solution, exhausts efforts to sustain conversation or, reaches a conclusion in a short time, students are free to move on to the next group; if it takes longer, people keep talking as others join in and/or leave independently (Heft, 2005).

\subsection{The One Law}

OST offers students free choice and accountability in learning. The Law of Mobility reminds participants that if they are neither learning nor contributing to a group, they must leave and join a session in progress where they feel more useful and inspired or not (Corrigan, 2002). In practical terms, Owen states that the law reminds people, "Don't waste time!" 
(1997). The Law of Mobility sits at the heart of OST: participants can enter or leave a conversation when and if they choose; thereby, taking full responsibility for their own contributions and learning. Consequently, OST reduces the likelihood of an individual or particular interest from exerting control or dominating a group as people are always free to leave and find a place where their voice can be heard (O'Connor, 2005). The OST facilitator posts the four principles and one law for all to see and reviews them during the opening circle.

\subsection{The Structural Flow}

The OST design has three phases. First, from the opening circle, individuals voluntarily create an agenda by posting a topic of interest on a community bulletin board, noting a meeting time and a place to convene the conversation. There is no limit to the number of topics that may be posted; however, the facilitator asks that those posting topics be passionate enough about the topic to host a conversation about it. Then, the remaining participants sign up to work on the issues that are of most interest to them. This self-organization invites people to choose where they would most like to contribute while asking them to self-monitor their engagement through the Law of Mobility. Movement to another conversation is encouraged to ensure students continue to learn or contribute. Participants who choose not to join a conversation immediately become, in Owen's terms, Butterflies and Bumblebees. Owen described Butterflies as "centers of non-action" (1997, p. 100); yet, their mobility speaks to actions like moving through the space, listening in on conversations, and sharing energy with a group albeit non-verbally. These participants, much like the social butterfly may visit many small groups, choosing to remain on the periphery of the conversations and to make occasional contributions. Bumblebees, on the other hand, like their namesakes in nature, are participants who move from one group to another cross-pollinating ideas among them as they go (Owen, 1997). Significantly, all participants contribute in the complex system as they engage in one or multiple conversations or enact the Law of Mobility as Butterflies and Bumblebees.

During the second phase, the convener of the session hosts the conversation and records ideas so that they can be shared with everybody. These notes become the Book of Proceedings for the session and provide an account of the conversations. In some instances, only the person who announced a topic shows up for the conversation at the specified time. In this case, the convener has several options: He or she may choose to sit alone, reflect on the topic and write notes to contribute to the proceedings, or join with another related conversation topic, or drop the original topic altogether as an indication that, at this time, no energy for the topic is present in the room. The topic is included in the OST proceedings so that it does not get lost and others may return to it at another time. Throughout the meeting phase, the facilitator remains largely in the background, possibly acting as a resource for logistical concerns but primarily holding space for the participants to ensure the space is safe for openness and creativity (Owen, 1997, p. 109). The facilitator does not try to persuade any participant to engage in OST. In a public setting, given full freedom of choice, participants may decide to leave the session or not attend in the first place. This would indicate that the initial invitation was not meaningful to the participant. In an educational setting, the obligation to attend school limits students' freedom; however, the option to invoke the Law of Mobility within the learning system acknowledges the accountability or responsibility of each student to participate and contribute in a way that is personally meaningful.

In the third phase, a closing circle concludes the OST session. The participants reconvene in the original opening circle formation to reflect on their involvement in the conversations. Similar to how teachers might hold a debriefing session in the synthesizing phase of their lesson (Zevenbergen, Dole \& Wright, 2004) to draw upon shared experiences and insights with students, the facilitator calls upon participants to focus on key ideas. Rather than a show and tell this phase should "engage the students in rich, productive discussion centered on the intended learnings" (2004, p. 73). Notably, teachers in the progressive tradition often act comparably to facilitators in OST (Boaler, 2009; Cobb, Wood \& Yackel, 1993; Davis \& Sumara, 2006; Ernest, 1999).

The facilitator provides opportunity for each participant to make comments if they wish around the circle. Often a talking tool is passed from one person to the next to focus participants on individual speakers. Participants are encouraged to share a word, a phrase or a comment on their experience in the conversation circle. All participants have an opportunity to 'pass' if they would prefer not to share orally. The facilitator encourages those who pass to include a written comment or reflection that will be included in the final compilation of the proceedings. Additionally, after participants review the book of proceedings, the facilitator may also ask participants to highlight commonalities among the results of the conversations and then to cast votes identifying the issues or opportunities that resonate most, thereby gauging the collective energy for ideas. Given a collection of stickers, participants may choose to place a sticker on each of the topics that they support or place multiple stickers on topics that they feel most passionate about (Herman \& Corrigan, 2002). This provides a strong visual record of the collective interests and presents a focus for next steps or decision-making. 


\subsection{Adaptations to OST in the Elementary Classroom}

Situating OST within an educational setting required several adaptations. These included attending to logistical issues involving classroom activity as well as research interests, acknowledging curriculum demands and modifying the teacher's instructional role.

The most significant adaptations revolved around the logistics. I needed to modify these elementary classroom OST sessions, primarily, in four ways: (1) to fit within the existing format of the school timetable; (2) to accommodate mandatory participation; (3) to adopt themes aligned to the curriculum; and (4) to add recording devices for research purposes. Time constraints led the OST sessions to be significantly shorter than might be expected with a different organizational structure. Where an organization or business might structure an OST event over the course of one to several days, the demands of the school timetable meant that students were held to 45 -minute and one-hour sessions. I compensated for this by holding four OST sessions over the course of eight weeks, always during the mathematics time slot. This adaptation was a limiting factor to the depth of conversations; however, as observed, students participated readily in the OST sessions and showed an increase in their math talk generally.

Although voluntary participation is a critical aspect of OST, this was not offered as an option to the elementary students. Given the importance of voluntarism to maintain engagement in learning and contributing to conversations, this was initially a concern; however, the novelty of the methodology to this classroom, the Law of Mobility and the ability to be a Butterfly, ensured that student engagement remained high. Therefore, I did not need to compensate for this adaptation. The methodology itself accommodated this constraint.

A slight adaptation was also required around the overarching themes. Today's curriculum requires teachers to plan each mathematics strand thoughtfully to ensure all outcomes are met. Therefore, working with the classroom teacher beforehand, we agreed to work with the mathematical curriculum in use. Therefore, the OST themes came directly from the current curriculum, rather than arising from student issues or opportunities. The first OST session focused on Numbers \& Operations; the second, on Patterning; and the third on Problem Solving. This enabled me to align with the teacher's instructional plan and to maintain continuity by addressing the current concepts with which the students had been working. Subsequently, the OST sessions were introduced to students as consolidation of their learning of the mathematics content; and, therefore, maintained the curricular flow of the classroom. Despite this adaptation, OST's decentralized control was preserved, as students remained responsible for how the agenda (or lesson) was created. They were invited to offer topics aligned to the pre-determined theme and had autonomy over these topics. Whatever they posted created a focus for a circle conversation, which they convened, leaving the teacher-authority to hold the space for self-organization. 


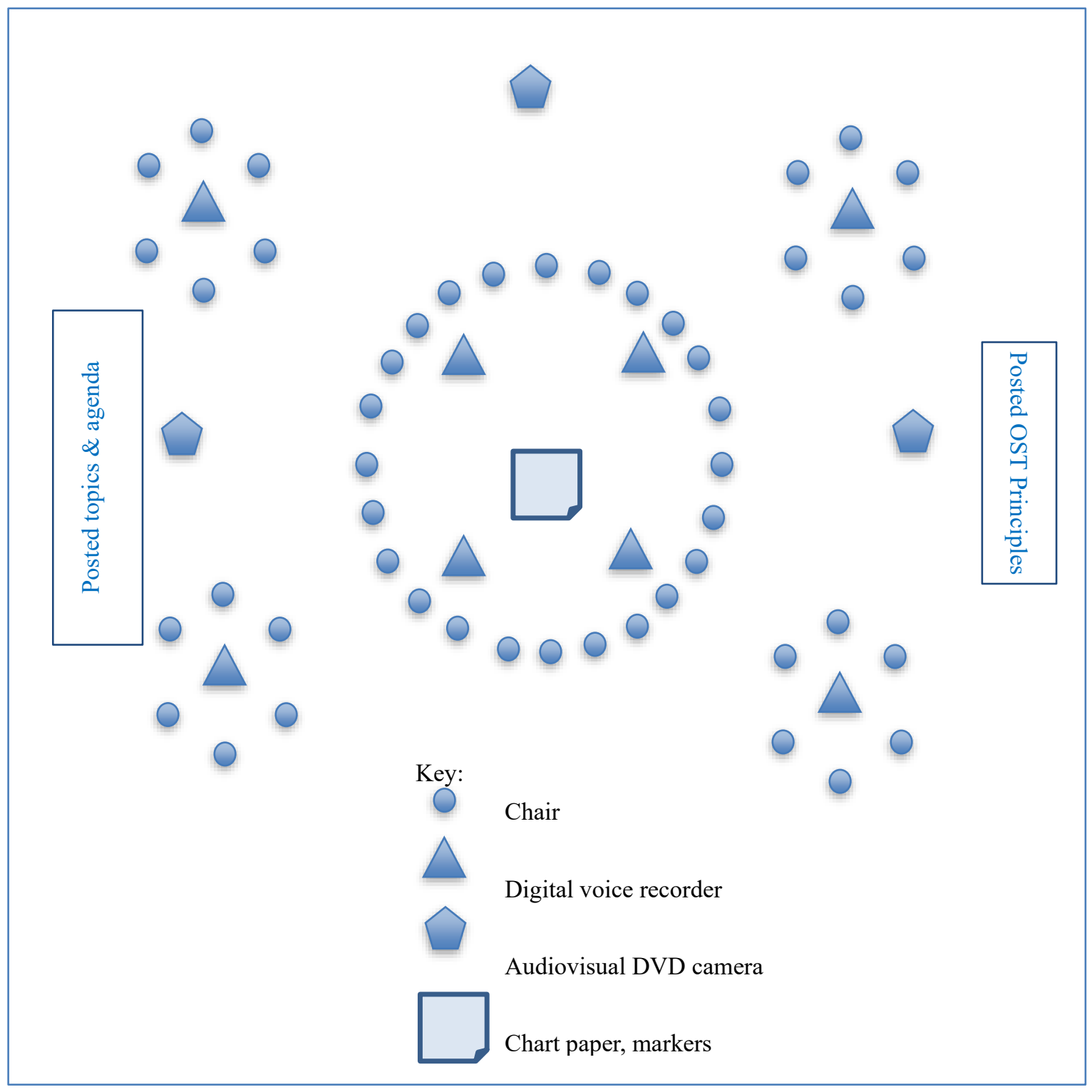

Figure 4. Placement of audio and visual recording devices for educational research

Finally, the last adaptation, served my research purpose and involved documenting the movements and discussions. I placed audio and visual recording devices (Figure 4) strategically throughout the space to provide data for discourse analysis of the OST intervention.

Both the video and the audio records were instrumental in understanding the overall dynamics of the sessions, as well as intimate interactions within the smaller conversation circles. It made the collective visible. Without this documentation, seeing and hearing the system overall would have been impossible. In addition, this adaptation was essential for a deep analysis of the meaningful exchanges. I compensated for this adaptation by conducting a trial run to ensure the students' understanding of the OST format and to increase comfort with the equipment to minimize the impact of the technology on behavior.

The emergent data confirmed that the adaptations had been adequate to support fruitful math talk. Below, I will describe how a review of the video recordings led to the development of classroom maps, which made visible both the students' physical interactions and those pertaining to content. Further, I also present excerpts of the audio recording to demonstrate the types of math talk.

\section{A Summary of Findings}

Complexity thinking offers a theoretical perspective from which to view, with fresh eyes, students as a collective in the 
mathematics classroom. The OST methodology, as an example of complexity in action, promotes the minimum conditions for complexity and provides teachers with a practical option for stimulating and sustaining conversation. My research asked: How might OST promote student participation to build learning communities that foster the discourse of mathematics? Data transcripts and classroom mapping indicate an increase in student participation in the OST sessions, where students participated with mathematical concepts and with each other differently, compared to the conventional classroom. As well, an analytic framework shows significant and complex conversations among students emerging through OST that suggest how complexity in action may hold exciting possibilities for learning mathematics. Below, I describe the analysis and classroom mapping tools, with examples from the OST intervention, for teacher-researchers who wish to investigate, at a deeper level, classroom interactions and mathematical discourse development.

\subsection{Classroom Mapping}

To visualize the impact of OST on the classroom, I developed a classroom mapping tool (Author, 2018) using visual recordings. These classroom maps reveal the movement and interaction among the students, including hubs of activity that

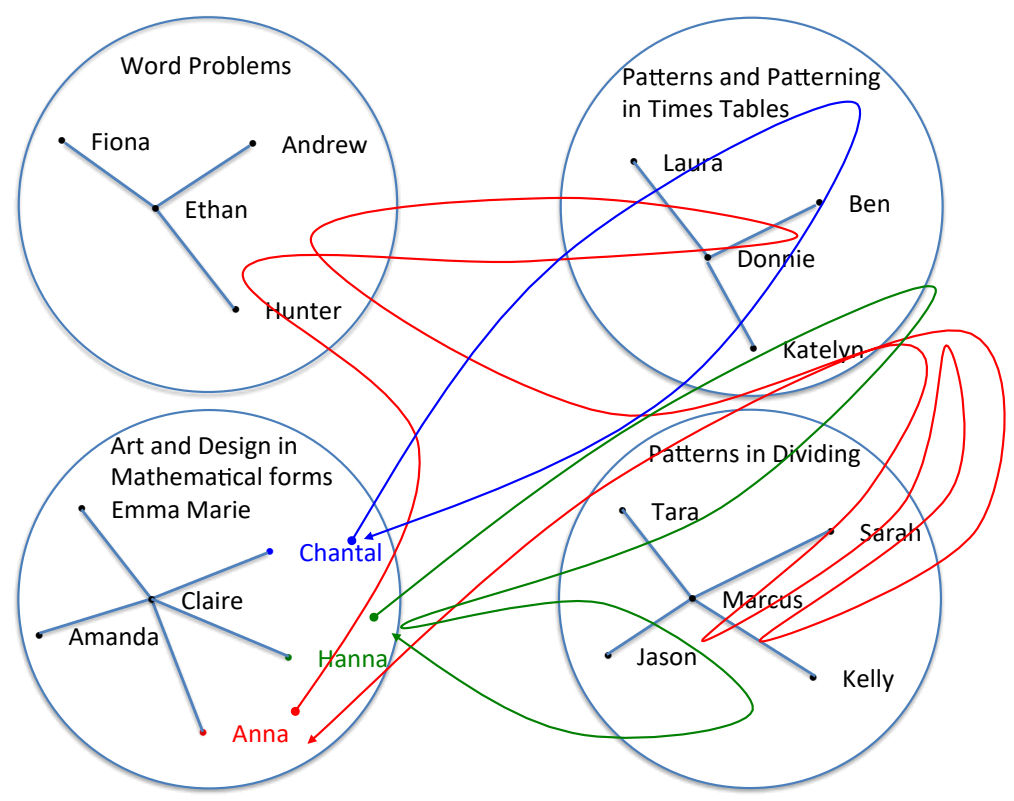

Figure 5. Classroom mapping: Movement from art and design in mathematical forms to other groups

emerged as students self-organized around topics of greatest interest. I assigned a specific colour to each student and, using the drawing tools from Microsoft PowerPoint (PPT), I created a visual representation of each student's movement (Figure 5). In this specific example, I show the movements from the Art and Design in Mathematical Forms conversation, convened by Claire, to the other three conversations. This mapping tool makes visible the intricacies of the web (or network) of interactions, as the law of mobility is applied; in this case, the convener's (Claire) insistence that things be done her way, which was ascertained from the audio recordings, likely motivated the movement to other conversations.

Classroom mapping was also useful to account for the movement of students choosing to adopt butterfly or bumblebee roles. Significantly, the mapping of the Word Problems group showed significant movement of all four participants to other groups; however, it also showed that all chose to return to the Word Problem conversation before the end of the session (Figure 6). Without this mapping tool, tracking movement and seeing the impact on learning would be impossible. In this instance, the video, combined with the audio recordings, showed that all came back to share with each other what they had learned from the other conversations; and, used ideas from other groups to generate new word problems for discussion. 


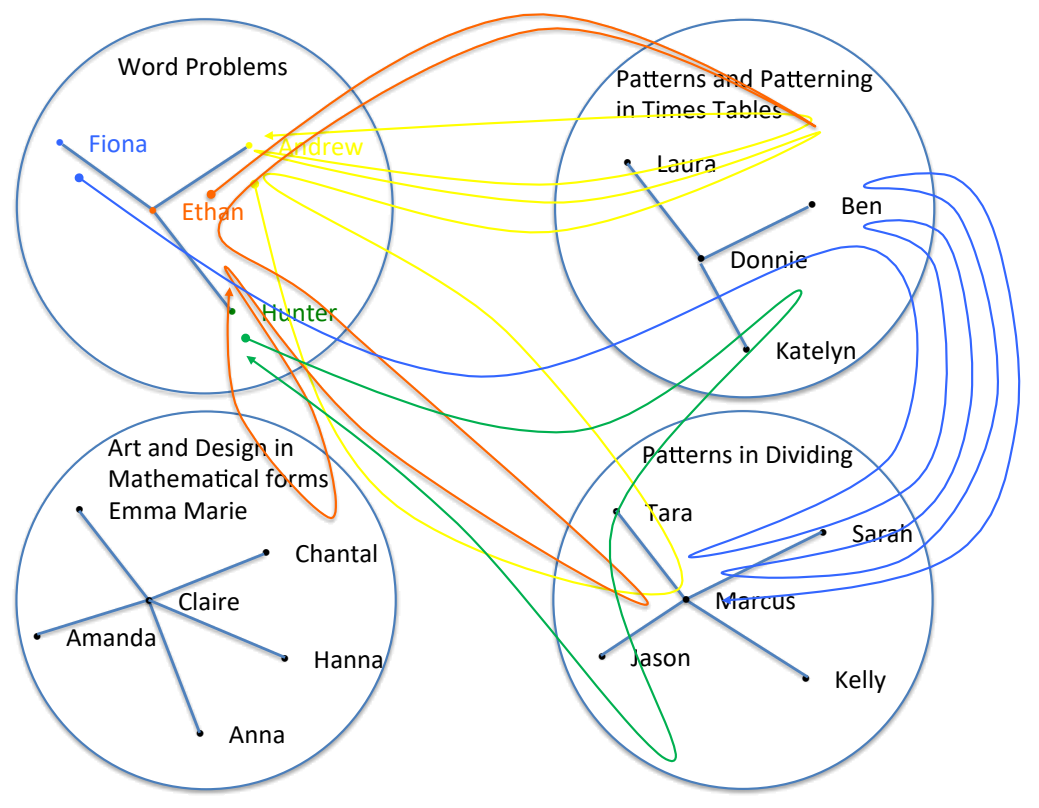

Figure 6: Classroom mapping: Movement of students from word problems group

Classroom mapping captures the choice afforded to students in OST. Despite this freedom, the decentralized classroom does not dissolve into chaos, as the minimum requirements provide enough structure to generate productive interactions. Students are invited to be personally accountable for their and others' learning; and, as these maps show, when presented with an opportunity for meaningful engagement, most participate and welcome opportunities to collaborate and explore areas of mutual interest. Observing the classroom from a distance, the movement may look chaotic; however, the maps, supported by the audio recordings, reveal purposeful conversation.

Within the parameters of the elementary school mathematics classroom, OST's minimum conditions enable decentralized control. Having just enough structure to encourage interaction may limit the number of students who check out or disengage; and may, quite significantly, increase overall student engagement, particularly for those students who are challenged by more routine disciplinary measures. Above, Figure 6 shows Hunter's efforts (in green) to cross-pollinate across three groups, indicating his desire to engage in conversation, despite his difficulty in listening and attending to others in the traditional classroom, as reported by the teacher. Often, the impact of his contributions was not immediately felt; yet Hunter's offerings (e.g., interjecting, reinforcing group activity, supplying positive energy), albeit in an unexpected, unconventional or perhaps, unintentional manner, created significant results for students' subsequent explorations. This was also clear in the second OST session, when Hunter joined the Addition Group and asked an important question, "Can we do the minus thing?" hoping to cross-pollinate and integrate a strategy from his Subtraction conversation (Figure 7). 


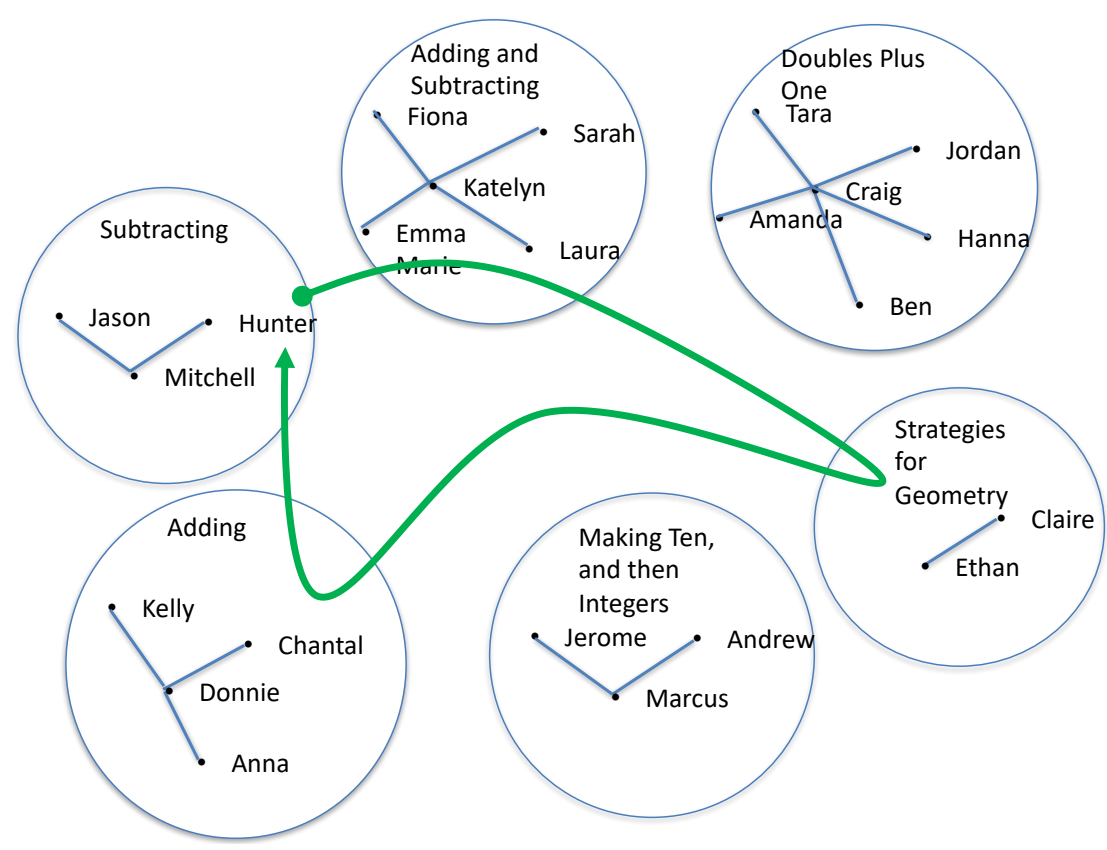

Figure 7. Classroom mapping: Movement of Hunter, the bumblebee, from subtracting group to adding group Hunter's question suggests a new direction for the group and a possible connection between the two groups. Two students block Hunter's suggestion, and so, he announces his departure without pursuing the idea further. Classroom mapping shows his return to the Subtraction group, which leads him to miss the subsequent comments by two other students, Anna and Chantal, who propose a take up of Hunter's suggestion. These students demonstrate an openness to new possibilities and readiness to explore ideas. Hunter has successfully cross-pollinated among the groups and regenerates the group's problem-solving efforts. In this case, Hunter, the Bumblebee, does not know the result of his interaction and does not realize his success in cross-pollinating.

In Figure 6, Fiona (in blue), similarly, does not immediately feel the impact of her contributions; yet she successfully cross-pollinates between two groups focused on patterns. We hear this in the conversation transcript (Table 1).

Table 1. Extract from Adding and Subtracting Group Transcript

\begin{tabular}{l|l}
\hline Fiona: & \\
\hline Katelyn: & What about word problems like what we were doing? \\
\hline Fiona: & Word problems? ... We've got times tables. They're ... \\
\hline Katelyn: & $\begin{array}{l}\text { I think that times tables and patterns mixed together...go... you can put } \\
\text { them together in problems. }\end{array}$ \\
\hline Fiona: & Times tables are something like patterns... \\
\hline
\end{tabular}

Fiona's important contribution, acting as a Bumblebee in OST, lends richness and variety to discussions. Even in this concise exchange, the conversation benefits from Fiona's initial inquiry. With her question, Fiona offers to share from her previous conversation. She is immediately blocked by Katelyn; yet, she proceeds with a proposition to build on the topic of patterns, the general topic of both groups. Katelyn finally accepts Fiona's conjecture and acknowledges her contribution. Katelyn builds upon this question, while Fiona explores a possible new concept (e.g., dividing) to expand the conversation even further. Classroom mapping shows Fiona's pathway predominantly alternates between these two patterning groups. Even when met with substantial blocking (see Table 6), Fiona persists to bring new strategies to these problem-solving groups, resulting in opportunities for meaningful exchanges among her peers.

\subsection{Analytic Framework}

In exploring the pedagogical implications of OST, I identified three types of conversation: sharing information, building knowledge, and exploring possibilities. These distinctions were useful in identifying the progression of student math talk in OST. Below, I describe these in further detail. I provide examples and show a lexicon to help other teacher 
researchers identify these aspects of discourse, arising from circle conversations, to make this identification and subsequent analysis easier. Below is a high-level overview, followed by examples to fully explain these types of conversation.

Students demonstrate sharing when they offer a personal reflection or story to others, articulate their personal perspective, or put an idea out on the table for all to consider. Others may respond to clarify ideas through questions, sharing their own experience or simply agreeing or disagreeing.

Building behaviors include students accepting an offered idea as a foundation, upon which another idea is built. Re-voicing, also a building behavior, demonstrates support for an idea by paraphrasing, thereby elevating the idea and offering a new invitation for others to work with the idea. Building also includes summarizing ideas to move toward convergence. The function of creating such a snapshot allows other students to begin the process of consolidation.

Exploring surfaces as students express interest in new topics, raise questions about what might happen, if they tried something new, test out and evaluate ideas. This playfulness indicated student engagement and productive participation, advancing their conversations with creative energy and original ideas.

I also identified another behavior labelled blocking, a term I used in the previous section of this article. In blocking, students display behavior designed to inhibit ideas, disrupt tasks or prevent forward movement. In my data, there were clear examples of unhelpful interruptions or comments designed to reduce the speaker's status (e.g., "you don't know", "that's stupid"); and even one example of a convener forcing their group to conform to their pre-determined ideas to how the conversation should go. Below is my analytic framework (Table 2), featuring examples of each type of conversation to assist with classroom observations for the teacher researcher.

Table 2. Analytic framework for OST observations

\begin{tabular}{|c|c|c|c|}
\hline Sharing & Building & Exploring & Blocking \\
\hline $\begin{array}{l}\text { Initiating or Offering (giving } \\
\text { information, sharing an } \\
\text { opinion or example) }\end{array}$ & $\begin{array}{l}\text { Elaborating on ideas } \\
\text { (adding-on to or } \\
\text { complementing ideas) }\end{array}$ & $\begin{array}{c}\text { Playing with ideas } \\
\text { (Conjecturing about future } \\
\text { possibilities) }\end{array}$ & $\begin{array}{l}\text { Telling more than } \\
\text { listening }\end{array}$ \\
\hline $\begin{array}{l}\text { Storytelling (relating } \\
\text { personal experience) }\end{array}$ & $\begin{array}{l}\text { Building through reasoning } \\
\text { (strengthening personal } \\
\text { opinion) }\end{array}$ & $\begin{array}{l}\text { Challenging opinions of } \\
\text { others (asserting personal } \\
\text { voice and space) }\end{array}$ & Interrupting \\
\hline $\begin{array}{l}\text { Clarifying ideas } \\
\text { (checking in) }\end{array}$ & $\begin{array}{c}\text { Linking ideas (organizing } \\
\text { thinking, building } \\
\text { mathematical context) }\end{array}$ & Testing out ideas & $\begin{array}{c}\text { Controlling space and } \\
\text { conversations } \\
\text { (taking over, } \\
\text { physically and } \\
\text { verbally) }\end{array}$ \\
\hline $\begin{array}{l}\text { Commenting on ideas } \\
\text { (agreeing, disagreeing) }\end{array}$ & $\begin{array}{c}\text { Interpreting ideas } \\
\text { (explaining, re-voicing, } \\
\text { summarizing) }\end{array}$ & $\begin{array}{l}\text { Evaluating (appraising } \\
\text { proposed arguments) }\end{array}$ & $\begin{array}{l}\text { Inhibiting (rejecting } \\
\text { ideas) }\end{array}$ \\
\hline $\begin{array}{c}\text { Asking questions } \\
\text { (encouraging others to share } \\
\text { ideas) }\end{array}$ & $\begin{array}{c}\text { Generating ideas } \\
\text { (encouraging others to build } \\
\text { on ideas) }\end{array}$ & $\begin{array}{l}\text { Requesting reasoning from } \\
\text { others (encouraging others to } \\
\text { explore ideas) }\end{array}$ & $\begin{array}{l}\text { Defensive body } \\
\text { language }\end{array}$ \\
\hline $\begin{array}{l}\text { Connecting with current idea } \\
\text { (receiving an idea) }\end{array}$ & $\begin{array}{c}\text { Contextualizing (orienting } \\
\text { through broader } \\
\text { perspectives) }\end{array}$ & Justifying personal reasoning & $\begin{array}{l}\text { Insisting on a certain } \\
\text { direction for the } \\
\text { conversation }\end{array}$ \\
\hline $\begin{array}{l}\text { Contributing mathematical } \\
\text { procedures through routines }\end{array}$ & $\begin{array}{l}\text { Constructing mathematical } \\
\text { concepts through narratives }\end{array}$ & $\begin{array}{c}\text { Problem solving with } \\
\text { strategic thinking (applying } \\
\text { knowledge) }\end{array}$ & $\begin{array}{c}\text { Telling people what to } \\
\text { do }\end{array}$ \\
\hline $\begin{array}{l}\text { Accepting others words and } \\
\text { ideas }\end{array}$ & $\begin{array}{l}\text { Representing through visual } \\
\text { mediators }\end{array}$ & $\begin{array}{c}\text { Reviewing outcomes } \\
\text { with new representation }\end{array}$ & Changing the subject \\
\hline $\begin{array}{l}\text { Making observations and } \\
\text { listening }\end{array}$ & $\begin{array}{l}\text { Making judgments based on } \\
\text { evidence, data, and/or model }\end{array}$ & Self-reflecting on opinions & $\begin{array}{l}\text { Judging other offered } \\
\text { ideas }\end{array}$ \\
\hline
\end{tabular}

\section{Discussion}

\subsection{Sharing}

Sharing promotes student accountability for learning through the pursuit of personal needs and interests and encourages connections with peers by fostering individual contribution more effectively. Sharing behavior was a first indication that OST might offer an alternative for students challenged with the regular routine of schooling and authoritative directives designed to reach pre-determined outcomes. In the exchange below (Table 3), three girls create and talk about addition 
strategies as they share information and opinions with each other:

Table 3. Extract from Adding Group Transcript

\begin{tabular}{l|l|l}
\hline & & \\
\hline Kelly: & My strategy is like crazy. & Sharing an opinion \\
\hline Chantal: & You never know the answer. & Shared knowledge \\
\hline Kelly: & $\begin{array}{l}\text { It's plus 2 and plus 1 take away 1 plus 3 } \\
\text { minus 6 }\end{array}$ & Sharing an example \\
\hline Anna: & Mine is simple. & Sharing an opinion \\
\hline Kelly: & You just have to add minus one. & Shared knowledge \\
\hline Hunter: & What are you working on? & Encouraging sharing \\
\hline Anna: & $\begin{array}{l}\text { Right now we're working on addition } \\
\text { strategy. }\end{array}$ & Shared knowledge \\
\hline Kelly: & You can come in if you want. & Inviting sharing \\
\hline Chantal: & Ok, We're taking your strategy. & Sharing from others \\
\hline Anna: & $\begin{array}{l}\text { My strategy is plus 7 plus 2 plus 1 take } \\
\text { away 3 minus 6 }\end{array}$ & Shared knowledge \\
\hline Kelly: & We should use times tables. & Sharing connection \\
\hline & &
\end{tabular}

Using common language facilitates sharing, as students attempt to devise original problems for others to solve. In this example, the focus is to answer a mathematical question. The exchange underscores two features of the conversation: the sharing of ideas and the acceptance of ideas. OST offers a conversational approach to instruction by emphasizing participants (Whoever comes is the right person) and providing opportunities to relocate within the space (Law of Mobility) as heard in Hunter's interjection above. In OST, students determine their own actions rather than a 'teacher-directed' lesson structure. When teachers provide this flexibility for students, new opportunities may arise to make connections with each other and with the subject area itself. Sharing in this way may increase students' participation and also strengthen a network of mathematicians that take up the contributions of others in a meaningful manner.

\subsection{Building}

The OST intervention also opened a space for students to participate more fully and actively in building mathematical knowledge with each other, as they assume collective responsibility for their work. In Table 4, Ethan makes an initiating move to engage his group in building a word problem together. Notable here is an indication of the source or 'voice' of mathematics arising from the students, as they independently undertake creating a problem within the context of a recent exchange about wrestlers. In the conventional classroom, this voice would more likely be heard from the teacher or text and not from the problem solvers themselves. In this way, we hear the voice of students as mathematicians at work:

Table 4. Extract from Word Problems Group Transcript

\begin{tabular}{l|l|l}
\hline & & \\
\hline Ethan: & We can make up a word problem. & Building mathematical context \\
\hline Fiona: & Let's make up a word problem. & Building connection \\
\hline Ethan: & Ok, Andrew? & Encouraging others \\
\hline Andrew: & Yeah. & Agreeing \\
\hline Fiona: & Where do you do your work? & Clarifying \\
\hline Ethan: & $\begin{array}{l}\text { In your journal. We can use the } \\
\text { wrestlers. }\end{array}$ & Orienting \\
\hline
\end{tabular}

Building problems together also arose in other conversation circles. The experience for Ben and his peers in the conversation below (Table 5) provided opportunities for students to think actively, to 'own' their work, and to take 
responsibility for completing it efficiently and accurately. The OST session provided the space for these students to choose freely their areas of interest and the manner of their contributions, with the purpose of building knowledge together by conversing within a collaborative setting. OST changed the nature of the work in the mathematics classroom and prompted students to take up the role of mathematicians, making and finding patterns rather than calculating answers to textbook problems.

Table 5. Extract from Patterns and Patterning in Times Tables Group Transcript

\begin{tabular}{l|l|l}
\hline & & \\
\hline Katelyn: & Ok wait, so what's our numbers? & Organizing thinking \\
\hline Ben: & Put 8 fives down and look at the pattern... & Building through reasoning \\
\hline [unknown]: & Times table. & Contextualizing \\
\hline Ben: & $\begin{array}{l}\ldots \text { and then you do the same thing with that... so, 20. Isn't } \\
\text { that cool } ?\end{array}$ & $\begin{array}{l}\text { Constructing } \\
\text { concepts }\end{array}$ \\
\hline Katelyn: & $\begin{array}{l}\text { Hannathematical } \\
\text { put that bar and what it equals. }\end{array}$ \\
\hline Hanna: & $5,10$. & $\begin{array}{l}\text { Representing through visual } \\
\text { mediators, Organizing }\end{array}$ \\
\hline Katelyn: & Yeah. Just put that bar and what it equals. & Adding-on \\
\hline Hanna: & 10. & Linking ideas \\
\hline Katelyn: & $\begin{array}{l}\text { Then you put two bars together for 10... equals 20 and then put ... } \\
\text { then each equals 40. }\end{array}$ & $\begin{array}{l}\text { Building } \\
\text { context }\end{array}$ \\
\hline Hanna: & What do you mean like? & Clarifying \\
\hline Hanna: & Ohhhh.... & Connecting \\
\hline Katelyn: & Works out really cool. & Complementing ideas \\
\hline
\end{tabular}

\subsection{Exploring}

The OST methodology contributed to the students' perception of fun and play in mathematics. The minimum conditions and, specifically, the Law of Mobility encouraged greater interaction bringing about deeper levels of engagement, as students' comfort with the open space inspired them to try different strategies to familiar problems. In this exchange (Table 6), students from the Addition Strategies circle conversation explore new ideas:

Table 6. Extract from Addition Strategies Group Transcript

\begin{tabular}{l|l|l}
\hline & & \\
\hline Donnie: & Let's make up questions. & Exploring new possibilities \\
\hline Kelly: & Ok, can we do our own questions? & Encouraging others to explore \\
\hline Chantal: & Ok, I want to test something. & Exploring an idea \\
\hline Donnie: & $\begin{array}{l}\text { You need the answers. Put your name so } \\
\text { I know who did it. }\end{array}$ & Clarifying \\
\hline Anna: & You got them both right. & Evaluating \\
\hline Kelly: & You did too. & Evaluating \\
\hline Donnie: & They're both right, Kelly. & Reviewing \\
\hline Kelly: & $\begin{array}{l}\text { Are we making up more questions or are } \\
\text { we done? }\end{array}$ & Exploring options \\
\hline Hunter: & $\begin{array}{l}\text { Can we do the minus thing, like my } \\
\text { group? }\end{array}$ & Offering suggestion \\
\hline Anna: & $\begin{array}{l}\text { We should do a question like that or } \\
\text { something. }\end{array}$ & Exploring options \\
\hline Chantal: & Let's do a different strategy. & Exploring options \\
\hline Anna: & I can figure it out. & Self-reflecting \\
\hline
\end{tabular}

Students, in turn, encourage each other to explore and invent strategies to push the group's thinking further. The 
self-directed nature of Donnie's proposal speaks to the power of setting minimal conditions to generate participant accountability for learning thereby rendering the intervention of an authority unnecessary. At play are the principles of OST: whoever comes is the right person, whatever happens is the only thing that could have, and whenever it's over, it's over. Not knowing who might participate in his conversation or how, Donnie presents an open-ended task to the group. $\mathrm{He}$ appreciates the offers he receives and allows further input and suggestions to guide the group, including a question from Hunter, who has become a Bumblebee intent on cross-pollinating the group with an idea from his original conversation circle. As Anna and Chantal continue to explore this new possibility together with Hunter, Kelly's completion of Donnie's task signals a closure for her. The teacher authority does not have to assume responsibility for this level of classroom management; it is self-directed in OST and the accountability of students to manage their own learning is theirs.

\subsection{Blocking}

From a complexity thinking perspective, the condition of self-organization allows participants to freely choose where and how they will contribute. Met with others' efforts to block or inhibit contributions, OST participants are free to move to other conversations (and away from the blocking) to continue meaningful input as stated in the law of mobility.

Table 7. Extract from Word Problems Group Transcript

\begin{tabular}{l|l|l}
\hline & & \\
\hline Andrew: & Who's taking over? Ok, I'm taking over. & Controlling space \\
\hline Fiona: & $\begin{array}{l}\text { Ok. There's [sic] four pies. If there's four pies, } \\
\text { four people ate four quarters of the pie. How } \\
\text { much would be left? }\end{array}$ & Challenging others \\
\hline Andrew: & None. Zero. Zero. & Contributing solution \\
\hline Fiona: & $\begin{array}{l}\text { There's [sic] four pies and the people ate four } \\
\text { quarters. }\end{array}$ & Explaining \\
\hline Andrew: & Four pies? This is stupid. & Rejecting \\
\hline Fiona: & You don't know. & Inhibiting \\
\hline Andrew: & $\begin{array}{l}\text { Each person ate four pies. If there was } 10 \\
\text { pies... }\end{array}$ & Justifying \\
\hline Fiona: & $\ldots$ only four... & Telling more than listening \\
\hline Andrew: & Doesn't make sense. & Rejecting \\
\hline Fiona: & I'll ask Katelyn... & Inviting others \\
\hline
\end{tabular}

Blocking in this exchange (Table 7) inhibits exploring in that it creates a loss of focus so that ideas do not have a chance of being fully developed. Fiona and Andrew's talk overlaps as each struggle to hear the other. Words of rejection underlie Andrew's misunderstanding of the problem while Fiona's attempts to clarify go unheeded. Andrew is blocking by not listening fully or asking clarifying questions. Being overly assertive, based solely on a misinterpretation, Andrew frustrates himself and slows progress for the group. An option in OST presents itself for Fiona who chooses to pursue her problem with another group.

\section{Conclusions}

I brought OST to an elementary mathematics classroom in order to observe how this meeting methodology might promote student participation to build a learning community that fosters the discourse of mathematics. My analysis of classroom conversations primarily showed evidence of sharing, building, and exploring of math concepts among the students as they expressed their understanding in a variety of ways. I also observed evidence of occasional blocking when students prevented others from expressing themselves. However, the principles and one law of OST provided opportunity for students to move away when confronted with blocking and make contributions elsewhere.

OST offered an alternative for students challenged with the regular routine of schooling and authoritative directives designed to reach pre-determined outcomes. Sharing in conversation allowed particular students to become accountable for their own learning and seek out spaces and connections with peers where they were able to contribute more effectively and pursue personal needs and interests. OST afforded students increased freedom, mobility, and choice to engage and re-engage as desired. When teachers provide this flexibility for students, opportunities may arise to make connections, first, with each other and, second, with the subject area itself. Sharing in this way may increase students' participation and also strengthen a network of mathematicians who take up meaningfully the discourse of mathematics. 
In some cases, the sharing and building sequences, as described above, showed how students assumed more directive roles to get their points across and, on occasion, inhibited some peers from participating fully in the conversation. In other cases, however, the transcripts also revealed patterns of meaningful exchanges emerging among the students, as they became more engaged and intent on building knowledge together. Significant, in terms of viewing OST as complexity in action, was the extent to which students found self-directed opportunities to engage further with their peers in the newly created work of building mathematical knowledge collaboratively. Providing students choice, through self-organization, may increase the neighbor interactions among them necessary for knowledge to build and explorative play. OST may have prompted more playful student interaction and enjoyment through participation in mathematical conversations; thereby, fostering classroom discourse.

I recognize that these findings are in no way representative of all mathematics classrooms; yet, the opportunity to observe OST temporarily in this classroom has provided me with some insights for teaching and research that help me examine and challenge existing practices in an effort to develop innovative pedagogies (Nichols \& Cormack, 2016). Pre-service students and in-service teachers may benefit from understanding how OST provides the minimum conditions for complexity thinking and opens a space of possibility for students. This is especially beneficial in mathematics education, where students require encouragement to build and to communicate their knowledge, while making connections to the wider world. OST, as a meeting methodology, could provide space for students to come together in conversation and explore their mathematical thinking collaboratively. Through professional development and workshops, teachers will develop skills in facilitating their classroom through OST; thereby, creating better awareness of how freedom, choice, and accountability will support students and their learning.

Of course, OST is not without its limitations and, as we have seen, the parameters of the school timetable, curricular constraints, as well as particular student behaviors such as blocking all affect the methodology's effectiveness. Being mindful of these limitations, however, points to possible additional interventions that might alleviate some issues including:

1. Building capacity in students for conversation skills and productive discourse moves.

2. Providing support for teachers to develop integrated curriculum to ensure more student engagement where higher-order skills are taught by connecting multiple subjects to a unifying theme or issue.

3. Creating collaborative events for teachers to promote professional growth and focus specifically on opportunities like OST that might differentiate learning significantly, especially for students at risk of disengaging from the regular routine of schooling.

Teachers do not have the luxury of teaching whatever they want; however, how they choose to meet the outcomes of a rigorous mathematics curriculum is within their professional judgment. Therefore, seeing opportunities to combine multiple mathematics classes or to design a full or half-day OST intervention to address cross-disciplinary issues will integrate this methodology with the more traditional classroom approaches. Such integration will likely increase relevancy of the curriculum for students and will increase students' accountability in learning mathematics.

Doll's invitation to educators to re-examine their instructional practices in light of complexity has led me to consider the possibilities of OST, as complexity in action, for the mathematics classroom. Doll's explanation of curriculum (Doll, Fleener, Trueit \& St. Julien, 2005) from the Latin verb currere, meaning the running of the course, also reminds me of the active, participatory nature of learning and so focuses my attention on the experience of the learner. When this classroom met the minimum conditions of complexity thinking, created by OST, to generate self-organization, students increased their participation in mathematical activity and through sharing, building, and exploring gained mathematics knowledge.

To paraphrase Paulo Freire (1997), tomorrow's numerate learner understands how mathematics helps us read the world, connect with others in a complex knowledge network and communicate effectively through meaningful exchanges. The use of OST as a social technology for large-group facilitation may assist in this aspiration by creating space for students to share, build, and explore knowledge together and by opening the space of possibilities for future knowledge to emerge.

\section{References}

Atkins, S. L. (1997). Lakatos' proofs and refutations comes alive in an elementary classroom. School Science and Mathematics, 97(3), 150-154. https://doi.org/10.1111/j.1949-8594.1997.tb17358.x 
Bai, H., \& Banack, H. (2006). To see a world in a grain of sand: Complexity and moral education. Complicity: An International Journal of Complexity and Education, 3(1), 5-20. https://doi.org/10.29173/cmplct8741

Barabási, A. L. (2003). Linked: How everything is connected to everything else and what it means for business, science, and everyday life. New York, NY: Penguin.

Baran, P. (1964). Introduction to distributed communications networks. Retrieved from http://www.rand.org/publications/RM/baran.list.html

Baskin, K. (2005). Storytelling and the complex epistemology of organizations. In K. A. Richardson (Ed.), Managing organizational complexity: Philosophy, theory, application, (pp. 331-344). Greenwich, CT: Information Age Publishing.

Boaler, J. (2009). What's math got to do with it?: How parents and teachers can help children learn to love their least favorite subject. New York, NY: Penguin Books.

Camazine, S. (2003). Patterns in nature. Natural History, 112(5), 34-41.

Capra, F. (1996). The web of life: A new scientific understanding of living systems. New York, NY: Anchor Books.

Cobb, P., Wood, T., \& Yackel, E. (1993). Discourse, mathematical thinking, and classroom practice. In E. A. Forman, N. Minick, \& C. A. Stone (Eds.), Contexts for learning: Sociocultural dynamics in children's development, (pp. 91-119). New York, NY: Oxford University Press.

Corrigan, C. (2002). Open space technology and the legacy of education. Retrieved from www.chriscorrigan.com

Cross, R., Parker, A., \& Sasson, L. (Eds.) (2003). Networks in the knowledge economy. New York, NY: Oxford University Press, Inc. https://doi.org/10.1093/oso/9780195159509.001.0001

Dalke, A., \& McCormack, E. (2013). In search of the unpredictable: Complexifying the classroom in the age of globalization. Teaching and Learning Together in Higher Education, 1(8), 1-7. https://repository.brynmawr.edu/tlthe/vol1/iss $8 / 3$

Davis, B. (1996). Teaching mathematics: Toward a sound alternative. New York, NY: Garland Publishing, Inc.

Davis, B., \& Simmt, E. (2003). Understanding learning systems: Mathematics education and complexity science. Journal for Research in Mathematics Education, 34(2), 137-167. https://doi.org/10.2307/30034903

Davis, B., \& Sumara, D. (1997). Cognition, complexity, and teacher education. Harvard Educational Review, 67(1), 05-125. https://doi.org/10.17763/haer.67.1.160w00j113t78042

Davis, B., \& Sumara, D. (2005). Challenging images of knowing: Complexity science and educational research. International Journal of Qualitative Studies in Education, 18(3), 305-321. https://doi.org/10.1080/09518390500082293

Davis, B., \& Sumara, D. (2006). Complexity and education: Inquiries into learning, teaching, and research. Mahwah, NJ: Lawrence Erlbaum Associates, Publishers.

Davis, B., Sumara, D., \& Luce-Kapler, R. (2008). Engaging minds: Changing teaching in complex times, $2^{\text {nd }}$ edition. New York, NY: Routledge.

Davis, E. J., Smith, T. J., \& Lefore, D. (2008). Chaos in the classroom: A new theory of teaching and learning. Durham, NC: Carolina Academic Press.

Doll, W. E. Jr. (1989). Complexity in the classroom. Educational Leadership, 47(1), 65-70. http://www.ascd.org/ASCD/pdf/journals/ed_lead/el_198909_doll.pdf

Doll, W. E. Jr. (1993). A post-modern perspective on curriculum (Vol. 9). New York, NY: Teachers College Press.

Doll, W. E. Jr. (2012). Complexity and the culture of curriculum. Complicity: An International Journal of Complexity and Education, 9(1), 10-29. https://doi.org/10.29173/cmplct16530

Doll, W. E. Jr., Fleener, M. J., Trueit, D., \& St. Julien, J. (Eds.). (2005). Chaos, complexity, curriculum, and culture: A conversation. New York, NY: Peter Lang.

Ernest, P. (1999). Social constructivism as a philosophy of mathematics: Radical constructivism. ZDM, 99(2), 71-73.

Everett, K. (2011). Designing the networked organization New York, NY: Business Expert Press, LLC. https://doi.org/10.4128/9781606491966

Fleener, M. J. (2002). Curriculum dynamics: Recreating heart. New York, NY: Peter Lang. https://doi.org/10.1007/978-1-349-25349-4_25 
Fleener, M. J. (2009). [Review of the book Chaos in the Classroom: A new theory of teaching and learning, by E. J. Davis, T. J. Smith, \& D. Leflore]. Nonlinear Dynamics, Psychology, and Life Sciences, 13(4), pp. 467-470.

Freire, P. (1997). Pedagogy of the oppressed. New York, NY: Continuum.

Gleick, J. (1987). Chaos: Making a new science. New York, N.Y., U.S.A.: Viking.

Heft, L. (2005). The open space technology idea book. Retrieved from www.openingspace.net

Herbel-Eisenmann, B., \& Cirillo, M. (Eds.). (2009). Promoting purposeful discourse: Teacher research in mathematics classrooms. Reston VA: NCTM.

Herman, M., \& Corrigan, C. (Eds.). (2002). Open space technology: A user's non-guide. Retrieved from www.chriscorrigan.com

Johnson, S. (2001). Emergence: The connected lives of ants, brains, cities, and software. New York, NY: Scribner.

Kauffman, S. (1993). The origins of order: Self-organization and selection in evolution. New York, NY: Oxford University Press. https://doi.org/10.1007/978-94-015-8054-0_8

Kauffman, S. (1995). At home in the universe: The search for laws of self-organization and complexity. New York, NY: Oxford University Press.

Kidney, R. (Producer), \& Schepisi, F. (Director). (1993). Six degrees of separation (Motion Picture). USA: Metro-Goldwyn-Mayer.

Kiefer, K. (2006). Complexity, class dynamics, and distance learning. Computers and Composition, 23, 125-138. https://doi.org/10.1016/j.compcom.2005.12.003

Kieren, T. (2003). Embracing complexity in studying human knowing: An example from mathematics education. In B. Davis (Ed.), Proceedings of the First Conference on Complexity Science and Educational Research, Edmonton, AB: University of Alberta.

Kincheloe, J., \& Berry, K. (2004). Rigour and complexity in educational research: Conceptualizing the bricolage. Maidenhead, UK: Open University Press.

Lakatos, I. (1976). Proofs and refutations: The logic of mathematical discovery. Cambridge, MA: Cambridge University Press. https://doi.org/10.1017/CBO9781139171472

Maturana, H., \& Varela, F. J. (1987). The tree of knowledge: The biological roots of human understanding. Boston, MA: Shambhala.

Mirsky, L. (2014). The power of the circle. Educational Leadership, 71, 51-55. https://doi.org/10.1108/09578231311291431

Mitchell, M. (2009). Complexity: A guided tour. Oxford, UK: Oxford University Press.

Nathan, M. J., \& Knuth, E. J. (2003). A study of whole classroom mathematical discourse and teacher change. Cognition and Instruction, 21(2), 175-207. https://doi.org/10.1207/S1532690XCI2102_03

Newell, C. (2008). The class as a learning entity (complex adaptive system): An idea from complexity science and educational research. SFU Educational Review, 2(1), 5-17. https://doi.org/10.21810/sfuer.v2i.335

Nichols, S., \& Cormack, P. (2016) Impactful Practitioner Inquiry: The ripple effect on classrooms, schools and teacher professionalism. New York: Teachers College Press.

O'Connor, D. (2005). Participatory processes: Creating a 'marketplace of ideas' with open space technology. The Innovation Journal: The Public Sector Innovation Journal, 10(1), 1-14.

Olson, E., \& Eoyang, G. (2001). Facilitating organization change: Lessons from complexity science. San Francisco: John Wiley \& Sons.

Owen, H. (1997). Open space technology: A user's guide, $2^{\text {nd }}$ edition. San Francisco, CA: Berrett-Koehler Publishers, Inc.

Owen, H. (2000). The power of spirit: How organizations transform. San Francisco, CA: Berrett-Koehler Publishers, Inc.

Pierson, J. L., \& Whitacre, I. (2010). Intellectual work: The depth of mathematical discourse and its relationship to student learning. Paper presented at the annual meeting of the American Educational Research Association, Denver, $\mathrm{CO}$.

Prigogine, I., \& Stengers, I. (1984). Order out of chaos: Man's new dialogue with nature. New York, NY: The Free 
Press.

Radford, M. (2006). Researching classrooms: Complexity and chaos. British Educational Research Journal, 32(2), 177-190. https://doi.org/10.1080/01411920600568950

Seedhouse, P. (2010). Locusts, snowflakes and recasts: Complexity theory and spoken interaction. Classroom Discourse, 1(1), 4-24. https://doi.org/10.1080/19463011003750624

Senge, P., Cambron-McCabe, N., Lucas, T., Smith, B., Dutton, J., \& Kleiner, A. (2000). Schools that learn: A fifth discipline fieldbook for educators, parents, and everyone who cares about education. New York, NY: Random House.

Sfard, A. (2008). Thinking as communicating: Human development, the growth of discourses, and mathematizing. New York, NY: Cambridge University Press. https://doi.org/10.1017/CBO9780511499944

Smitherman, S. (2006). Reflections on teaching a mathematics education course. (Doctoral dissertation). Retrieved from ProQuest Dissertations \& Theses Full Text. (Order No. 3208200)

Smitherman-Pratt, S. (2009). Complex Conversations: Reflections on teaching a mathematics education course.

Stanley, D. (2009). Complex responsive processes: An alternative interpretation of knowledge, knowing, and understanding, Complicity: An International Journal of Complexity and Education, 6(2), 29-39. https://doi.org/10.29173/cmplct8812

Surowiecki, J. (2004). The wisdom of crowds: Why the many are smarter than the few and how collective wisdom shapes business, economics, societies, and nations. New York, NY: Doubleday.

Throop Robinson, E. (2018). Mapping complexity in an elementary mathematics classroom. Canadian Journal of Action Research, 19(3), 5-33. https://doi.org/10.33524/cjar.v19i3.423

Waldrop, M. M. (1992). Complexity: The emerging science on the edge of order and chaos. New York, NY: Simon \& Schuster. https://doi.org/10.1063/1.2809917

Weaver, W. (1948). Science and complexity. American Scientist, 32, 536-544. https://www.jstor.org/stable/27826254

Wheatley, M. J., \& Kellner-Rogers, M. (1999). A simpler way. San Francisco, CA: Berrett-Koehler Publishers, Inc.

Yorks, L., \& Nicolaides, A. (2006). Complexity and emergent communicative learning: An opportunity for HRD scholarship. Human Resource Development Review, 5(2), 143-147. https://doi.org/10.1177/1534484306287559

Zevenbergen, R., Dole, S., \& Wright, R. J. (2004). Teaching mathematics in primary schools. Crows Nest, NSW: Allen \& Unwin.

\section{Copyrights}

Copyright for this article is retained by the author(s), with first publication rights granted to the journal.

This is an open-access article distributed under the terms and conditions of the Creative Commons Attribution license which permits unrestricted use, distribution, and reproduction in any medium, provided the original work is properly cited. 